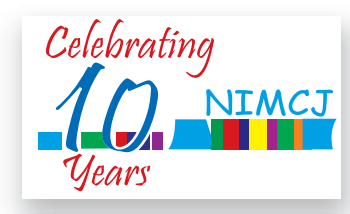

${ }^{1}$ Dr. Rowshan Jahan Akhter Assistant Professor (Peadiatrics) Dhaka Shishu Hospital

Dr. Kanta Chowdhury Registrar, Dept. of Neonatology Dhaka Shishu Hospital

${ }^{3}$ Dr. Saenat Haque Medical Officer Dhaka Shishu Hospital

${ }^{4}$ Dr. Ayesha Noor Medical Officer Dhaka Shishu Hospital

${ }^{5}$ Dr. Shekufe Zaman Medical Officer Dhaka Shishu Hospital

Correspondence Dr. Rowshan Jahan Akhter Assistant Professor (Peadiatrics) Dhaka Shishu Hospital Sher-e-Bangla Nagor Dhaka, Bangladesh e-mail: rowshanfairuz22@gmail.com

\title{
A Newborn with Maple Syrup Urine Disease
}

\author{
R J Akhter ${ }^{1}$, K Chowdhury ${ }^{2}$, S Haque ${ }^{3}$, A Noor ${ }^{4}$, S Zaman ${ }^{5}$
}

\section{Introduction}

Maple Syrup Urine Disease (MSUD) is an autosomal recessive organic acid/amino acid disorder due to a defect in the Branched Chain alpha-Ketoacid Dehydrogenase (BCKD) enzyme, which catalyses the breakdown of branched chain ketoacids. These ketoacids form from the breakdown of the branched chain amino acids (BCAA): leucine, isoleucine, and valine. As a consequence, the ketoacids and their precursor BCAA accumulate in blood with the toxic metabolic components being leucine and the ketoacid and excreted through urine., ${ }^{1,2}$ Maple syrup urine disease occurs in about 1 case per 185,000 live births. Within the Ashkenazi Jewish population, the incidenceis higher, at 1 per 26,000 live births. In select inbred populations (ie, the Mennonites in Pennsylvania), it may be as common as 1 case per 176 newborns. $^{3}$

\section{Case Report}

A 8 days old female neonate, $3^{\text {rd }}$ issue of a consanguineous parents was admitted into the neonatal unit of Dhaka Shishu Hospital, with the complaints of poor activity and reluctant to feed for 4 days and repeated convulsion for same duration.

The baby was delivered by LUCS at term (38 weeks) in a hospital without any complication. The baby cried immediately after birth and her birth weight was $2.7 \mathrm{~kg}$. Mother is a 32 years old lady, was under regular antenatal checkup. She had no history of Diabetes Mellitus, Hypertension, Bronchial Asthma or any other illness during her pregnancy period and she was duly immunized. This is her third issue. First issue is healthy but the $2^{\text {nd }}$ issue died at the age of 26 days who had been suffering from similar type of illness since birth. That issue was diagnosed as a case of MSUD.
After delivery, this baby was discharged from hospital with her mother on $4^{\text {th }}$ day of age and she was on breast feeding. Two days after discharge the baby developed reluctance to feed, lethargy and repeated convulsion. Convulsion used to occur 10 to 12 times a day and each time lasted for few (3-5) minutes. The seizure was characterized by stiffness of all four limbs and cycling movement of the lower limbs. With these complaints he was admitted into Enam Medical College Hospital at Savar and was treated there in NICU as a case of Neonatal Sepsis for two days. And was referred to ICU of Dhaka Shishu Hospital for further evaluation and better management.

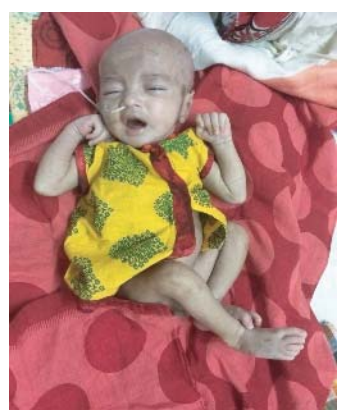

On examination, the baby was ill looking, lethargic with poor reflexes and activity. Dyspneic with suprasternal recession and chest indrawing, afebrile (temp- $98^{\circ} \mathrm{F}$ ), CRT $<3 \mathrm{sec}$, Heart rate was $136 / \mathrm{min}$, Resp. rate was $65 / \mathrm{min}$, Heart- $S_{1} \& S_{2}$ audible with no added sound. Lungs- crepitations present over right lung field. Had no visible congenital anomaly. Her weight was $2.6 \mathrm{~kg}$, length- $49 \mathrm{~cm}, 0 F C-35 \mathrm{~cm}$, and Anterior fontanel- wide open.

Provisionally we diagnosed the baby as a case of : Neonatal Sepsis with Pneumonia with Inborn Error of Metabolism-Maple Syrup Urine Disease (MSUD) in a Term Appropriate for Gestational Age (AGA) baby.

Differentially we thought of- 
- Neonatal Sepsis with Inborn Error of Metabolism (other than MSUD)

- Neonatal Seizure Disorder

- Neonatal Meningitis

Following Investigations were done at the day of admission.

CBC with film- Hb\%-15.7gm/dl, TC-7200/cmm, DC: N-50\%, L-31\%, M-08\%, E-01\%. Blood Film-RBC- Normocytic normochromic, WBC- Shows as distribution, Platelet- adequate.

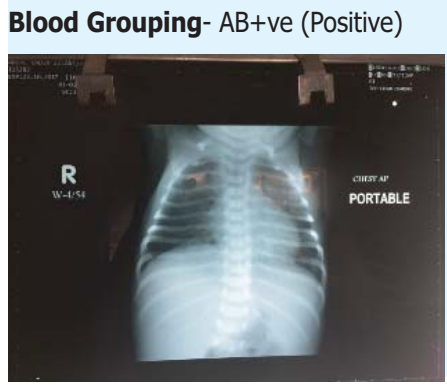

CXR- small patchy opacities ove both the lung fields

- Initial treatment was given with NG tube feeding

- Infusion $10 \%$ Baby Saline

- Injectable Antibiotics-Inj. Meropenam, Inj. Vancomycin, Inj Amikacin,

- Inj. Phenobarbitone,

- Oxygen inhalation

During Hospital stay, consultation was taken from the "Department of Neuroscience and Development Unit" regarding treatment and further evaluation. Then the following investigations were done according to their suggestions.

- S. Ammonia- $62 \mu \mathrm{mol} / \mathrm{L}$

- S.lactic Acid- $1.3 \mathrm{mmol} / \mathrm{L}$

- S.FT4- $11.77 \mu \mathrm{g} / \mathrm{dl}$

- S.TSH- $2.70 \mu \mathrm{U} / \mathrm{ml}$

- USG Brain- Diffuse brain edema suggestive of micro hemorrhagic foci in brain parenchyma.

- Echocardiography- PFO, shunting Left to Right with Mild LPA stenosis.

- CSF Analysis- Normal study.

- Urinary assay for metabolic disorder-

Urinary Ketones-Positive

DNPH (2,4-Dinitro-phenyl hydrazine) Assay- positive

Ferric Chloride Assay- positive

TMS- Newborn screening for Acyl carnitine- Amino Acid in plasma and DBS (Dried blood spot) revealed-Maple syrup urine disease confirming the diagnosis as Maple syrup urine disease.

Therefore our Final Diagnosis was : Term, AGA with Neonatal Sepsis with Pneumonia with Maple Syrup Urine Disease.

\section{Management}

We have mentioned earlier the management of the acute condition. Then

- Multidisciplinary approach is required for this patient i.e. Pediatric Clinician, Neurologist, Dietician and Counselorunitedly manage the baby.

- Counselingof parents was done regarding - the Disease inheritance, identification, treatment modalities and follow up.

- Diet (Advised by Dietician)

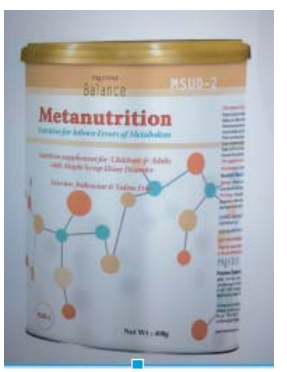

A special diet of low protein milk formula (MSUD-1 and 2) which is free of branched-chain amino acids, mainly Leucine, Isoleucine and valine. This special formula milk is not available in Bangladesh, parents brought it from India.

- Cofactor Supplementation was done with

- Tab Berin (Thiamine) - $100 \mathrm{mg} \quad 1+0+1$

- Tab Riboson (Riboflavin) - $2 \mathrm{mg} \quad 1+0+1$

- Tab Folic Acid (5 mg)

- Multivitamin Drop

Follow Up-was advisedat a regular interval (6-12 monthly) to monitor the Neurodevelopmental and Medical Parameters (any sign of metabolic derangement, convulsion, sepsis etc.).

Inborn Error of metabolism is not a very rare case anymore. We frequently come across cases of Inborn Error of metabolism. However, till now many cases remain undiagnosed due to overlapping symptom of other neonatal illnesses like asphyxia, sepsis etc. Therefore, we should be cautious about early diagnosis of similar illness. For that reason, routine new born screening is very much necessary for every neonate.

\section{References}

1. Podebrad F, Heil M, Reichert S, Mosandl A, Sewell AC, Böhles H (April 1999). "4,5-dimethyl-3-hydroxy-25H-furanone (sotolone)--the odour of maple syrup urine disease". Journal of Inherited Metabolic Disease. 22 (2): 107-114. doi:10.1023/A:1005433516026. PMID 10234605.

2. Ogier de Baulny H, Saudubray JM (2002). "Branched-chain organic acidurias". Semin Neonatol.7 (1): 65-74. doi:10.1053/siny.2001.0087. PMID 12069539.

3. Germaine L Defendi, Chief Editor: Luis O Rohena, Maple Syrup Urine Disease (MSUD): Background, Pathophysiology...updated May 2, 2018https:// emedicine.medscape.com/article/946234-overview

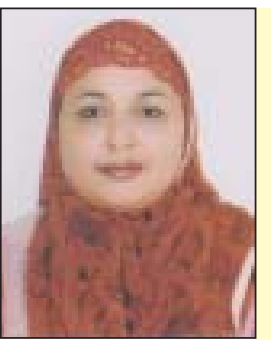

Dr. Rowshan Jahan Akhter passed MBBS from Bangladesh Medical College in 1998. Achieved DCH from Bangladesh Institute of Child Health under Dhaka University in 2006 and MD (Paediatrics) in 2015 from the same institute under Dhaka university. She is working in Dhaka Shishu Hospital since 1999, which is the largest children hospital in Bangladesh. She has experience of working as a study physician in a WHO project under John Hopkins University for three years. She had experience of presenting many scientific papers in different national and international seminars. She is the author of 20 national and international scientific papers so far. At present she is working as an Assistant Professor of general pediatrics in Dhaka Shishu Hospital. 